\title{
THE NEW ‘FACES’ OF THE EUROPEAN METROPOLIS AND THEIR GREEK VERSION
}

\author{
B. IOANNOU \& K. SERRAOS \\ School of Architecture, National Technical University of Athens, Athens, Greece.
}

\begin{abstract}
The aim of this study is to present significant 'faces' characterizing the physiognomy of the contemporary Greek city as it is shaped or being shaped at the moment. In this context, the term 'city face' is used as an analytic tool, acknowledging that the image of the city is nothing less than the material and concrete expression of the really complicated, immaterial urban dynamics and trends. The main argument is whether the diverse 'faces' of the European metropolis are reproduced in the Greek city as well, simultaneously or with a delay; and whether the Greek city follows its own particular evolution, presenting similarities or differences from the European case. At a first step, corresponding views or aspects of urban image at the European or the global level are presented to create a wider reference framework. The European city 'faces' considered in this study are: gentrified city, multicultural city, sustainable city, virtual city, and the city of a special identity. The second step is to define dominant urban 'faces' for the Greek city as well: the historic city, the planned and designed city, the unplanned/ arbitrary city, the rural city, the marginalized city, the natural city, and the globalized city. Our analysis, summarizing the conclusions of recent research and studies, has shown that the revealed new 'faces' of the Greek city, although a result of widespread external dynamics, correspond to more or less common aspects of urban evolution; in fact, they are motivated by different agents and conditions in the Greek paradigm than in the European one. So the future evolution may be in some terms differentiated.

Keywords: city face, European metropolis, Greek city, image, urban dynamics, urban evolution.
\end{abstract}

\section{INTRODUCTION}

All recent changes in the European metropolises pass through systematic evaluation to interpret urban images and forms and their connection to the current evolution, in terms of the social, economic, and technological field [1]. Approaches that attempt to organize and indicate cityscape transformations through their influence on the formation of a total city character are extremely interesting $[2,3]$. Aspects or views such as 'sustainable city'; the city of 'cohesion' or 'exclusion'; the city of 'megaevents' or 'daily urban life'; or even 'global city', 'net city', or 'virtual city' show that urban space is moving globally towards a new urban diversity.

The Greek city was strongly affected, during its recent evolution in the 20th century, by a variety of mostly indigenous - and fewer external - agents in a manner which has led to a remarkable diversity. Diversity is expressed in urban images and also in urban form and structure. New conditions are formulated in the framework of a unified European market; free population mobility and an unlimited communication capability lead undoubtedly to increasing effects from external or global constraints on every urban form or image, and on the reshaping of the total character and the particular 'faces' of the Greek city as well. These constraints were expected to act in the direction of applying a new global homogeneity.

In fact, new urban forms and images are affected by wider circumstances, are born and expand every day, creating new patterns of 'urban faces', on or next to the pre-existing indigenous diversity of the Greek city. These faces, newer or older, do not obviously appear at the same time and place. Somewhere or sometimes, they exist within the body of the Greek city, revealed less or more intensively, showing their presence and make up what is more precisely known as 'new physiognomy' or 'hybrid cityscape'. 
The current study - beginning from a short compendium of the new European urban patterns attempts to compare part of the contemporary image of the European metropolis to the Greek paradigm, in conjunction with the socioeconomic trends and corresponding changes. The main argument that arises in this framework is whether the diverse 'faces' of the European metropolis are reproduced in the Greek city as well, simultaneously or with a delay; and whether the Greek city follows its own particular and characteristic transition, presenting similarities or differences from the European case. Finally, this study also attempts to forecast the future perspectives of the Greek city.

\section{NEW URBAN FORMS AND FACES OF THE EUROPEAN METROPOLIS}

\subsection{Approaching future urban structures}

Late urbanization process in the postwar European space has led to the enlargement of mega-cities, which have now expanded beyond the administrative boundaries of their initial cores, are organized into many administrative districts, and have local and national governments with different capabilities and priorities [4]. On the other hand, the structure and the urban form of the conurbations have been consolidated, during the time, by a sum of coincidences and actions including, among others, the historical and political framework, the socioeconomic background, natural recourses, and technological evolution.

All these factors are still very crucial in any urban analysis, particularly if one wants to forecast the future evolution of city life, as many of the shifts and transformations of the past seem to be cyclic and repeatable [5]. For example, demographic evolution, technological advancement and innovation diffusion, inequalities in accessing technology, aggravation of the quality of life for the poor represent such repeatable procedures.

Thus, the structure of the future city can be investigated only by estimating future evolution of the basic constrains of the current trends. For example, the rapid spread of the core technologies (web, innovative telecommunications, etc.), the mobility and transportation conveniences, the intense and transforming role of 'centrality', the nodal role of 'city-gates' or 'city links', 'tunnel phenomenon' $[6,7]$, or the multiplication of 'gated cities' are some recent elements of the new mainstream. It seems that these are some of the trends shaping the future urban shifts worldwide, during this century.

At the same time, it seems that other issues based on a more traditional aspect, described among others in terms of 'urban sprawl', 'sub- and ex-urbanization', 'metapolis', 'the city region', 'urbanrural fridge' [8], 'spatial scales collapsing', etc., will continue to define the future evolutional dynamics of the cities.

\subsection{The shrinking and expansion of the city}

More recent discussions around the image of the future city, at a global level, raise arguments such as: 'will the cities be bigger or smaller?', 'will urban development be polarized or balanced?', and 'will economic growth and competitiveness be in an increasing or a decreasing mode?' [9]. Beyond the naive first impression these questions give, they raise a number of very serious issues related to the wider framework of the social evolution or the structural shifts in contemporary societies, the political or physical regime (physical disasters, wars, etc.), or particular issues such as the future capacity of urban infrastructure. Moreover, the future of the cities may be defined by the cities themselves, that is to say the local governments, the local economic and social actors, and the citizens.

Nevertheless, the primary argument, having extensions in all the above-mentioned fields and also in others, is related to the further expansion and housing stock enlargement of the European cities: will the European cities continue expanding to perpetuity? Relative research [5] shows that cities attract 
inhabitants and enterprises mainly because of the jobs offered and the opportunities they provide to increase personal or entrepreneurial income. Additionally, in most cities, large capital is invested to create infrastructure to assist urban expansion furthermore as well as city enlargement. At the same time, historical reviews have shown that cities that permanently declined or disappeared are found in very few cases. The 20th century is full of examples of cities that turned around, even after strong deindustrialization setbacks. Consequently, it is believed that metropolises will continue not only to exist but also to enlarge and expand depending on four basic dynamic agents: economic growth, social welfare, cultural advancement, and political stability [3].

\subsection{The degradation and gentrification of the city}

European cities, beyond the dynamic of their continuous expansion and development, have also met, in almost every historical phase, short periods of regression, at least in particular cases or certain urban areas. Such a precise example is the case of abandonment and redevelopment of the historical centers or the profitable allocation of mass retail, recreation, and free-time activities within degraded ex-industrial zones that were not in active land use. In this framework, the 'gentrification' process appears as a practice, already implemented, and is expected to continue more intensively for the next few years [10]. This is because it has been commonly adopted and supported through institutional mechanisms of public-private partnership for the regeneration of degraded urban areas and their colonization by high-income inhabitants or activities of intensive profitability. All these procedures are a part of the socio-spatial process of the generation of the new high-income classes and their spatial re-settlement or allocation to regenerated 'gentrified urban areas' [10].

A corresponding pattern of urban transformation is the 'totalizing suburb' [10]. It is a term used to depict the reshaping of traditional suburbs that were previously areas with high urban and environmental quality, for high- and medium-income classes, but at present have been converted into zones of retail, services, and recreation, creating job seats for the local inhabitants. Thus, even if many suburbs had, in the past, been characterized as 'bed cities' or zones exclusively for residential land uses, new 'integrated' suburbs are turning autonomous enough, which is certainly positive for their particular urban structure, but at the level of a conurbation, one could claim that it creates new centralities and conflicting spatial hierarchies, as in many cases these new centers attract services of metropolitan importance. This mode will definitely weaken the model of a monocentric conurbation and the notion of a clear hierarchy of centers in a large-scale metropolitan complex.

\subsection{The multicultural city}

The creation of pouches or nuclei of a clear, differentiated social/cultural character, within the European urban centers, is a great issue connected to both the indigenous dynamics of the urban population and the procedure of new inputs through migration.

More specifically, studies on this aspect have quoted five patterns of fragmented urban areas generated under the influence of the global socioeconomic dynamics [10]: postmodern 'acropolises' (large-scale architectural complexes), areas regenerated due to private sector forces and initiatives (gentrification), pouches of social exclusion, totalizing suburbs, ethnic or racial ghettos. With the exception of the degraded areas of this list, all other patterns refer to the processes of urban development, urban renewal, and urban expansion at the current moment, their recent past, and their nearby future.

The fragmented city, which is shaped through the mentioned patterns, has one really positive aspect [11], which derives from the fact that urban densities seem to be increased at the points where 
social groups or diversities are planted in these contemporary metropolises. Thus, the possibility of reinforcing social mixture and daily contact is also increased, benefiting tolerance, coexistence, and cultural interaction.

A main element of a cultural and civilization expression in cities is the presence of art in the public space. In the new era, where tertiary sector employees have become the largest group of citizens, where the new metropolises have to fight to maintain their glamour and their seat in the global hierarchy, art creation is considered more and more important in establishing meanings and identities [2]. Art and open space cultural activities are already covering a considerable part of the city economy. Therefore, it is estimated that artistic creativity can become the base of a new system of symbolism in the postindustrial 21 st century city, for the very obvious reason of its profitable nature in marketing and entrepreneurial life and its capability of appearing in different versions suitable for various needs and purposes [2].

\subsection{Sustainable city}

The global economy functions today, more than ever before, under unification forces, especially in terms of a global environmental impact. Environmental problems - local, regional, or international cause increasing damage on the global ecosystem, as the overexploitation of sources and resources is undefined and unrepaired. Based on this, we can define a 'sustainable city' as a city whose inhabitants, institutions, and enterprises would continuously try to improve the physical, built, and cultural environment in every spatial scale, while at the same time they would work under methods that support the goal for global sustainability [12].

Some important environmental directions for the urban space are contained within the term 'compact city' [13]. These are found, among others, in the need for rational management of urban land and the strategic planning for increasing urban densities to an energy saving level, sustainable waste and water management, sustainable mobility, encouraging pedestrian movement, and the use of means of mass transportation.

Furthermore, and beyond any clearly environmental demands, there is another aspect that describes the condition of the building mass which is also crucial: 'spatial motionless' - the condition in which an urban area is unsuitable for any shift. In many cases (e.g. historical centers), 'spatial motionless' [14] can be positively evaluated. There are many other cases (e.g. high-density degraded areas) in which such a condition retains the substantial disadvantages of aged constructions and dysfunctional plans of urban fabric.

\subsection{Virtual city}

A virtual, imaginary, or fictional city image is very often presented via cinema or television, either to illustrate the image of the future city (films such as Matrix, Blade Runner, Twelve Monkeys) or to promote several fancy urban images, corresponding to several marketing goals [9]. Therefore, the city image is a product that is being advertised and sold [15]. There are several specific cityscape patterns that tend to become dominant, at least through the media, such as the 'city of joy and fun' (places of consumption, warm climate, beaches, smiling citizens, blue sky, and glamorous buildings are some features that attract not only tourists but also investments), the 'green city' (quasi-urban environments, low densities, vegetation, nature, water, the notion of fresh air, absence of traffic), the 'city of culture' (luxury malls, concert halls, galleries, open-air music festivals), and finally 'multicultural city' (cultural diversity, virtual or fake multiculturalism with a notion of folklore). The above-mentioned versions can be seen as multiple or distributive aspects of the whole; views of one 
metropolitan conurbation forcing the visitor or the resident to build up their own special world in the city world [14].

Therefore, the importance of the attractiveness of urban space based more on its image and less on its function is progressively increased. This happens because of the intensified competition among European and global metropolises, the feasibility in communication and mobility, and the overall transition of social models and beliefs.

\subsection{The city of a special identity}

UNESCO's data [1] show that the consideration of architectural richness as a returning cultural resource has considerably implicated private initiative in planning and developing processes, especially as related to squares', buildings', and complexes' redesign and renaissance. The predominance of retail and recreation activities in the public space excludes at the same time any individuals or social groups to whom these activities do not attend to.

Another main identity element is the physical landscape, either as a zone surrounding urban space or as an area enclosed by urban fabric, having additionally the very significant property to differ from urban space homogeneity and, in many cases, the capability to retain its special identity, assisting it to escape from the alteration tensions affecting the neighboring built environment [16].

Cities of today are suggested to protect their historic and landscape identity through both built and natural recourses protection at the same time. The danger of loosing identity does not come only from globalization homogeneity or the international architectural style in general but also because of a particular inverse procedure known as 'heteroptopia' [17], which is the increased tolerance to reproduction and co-existence of different cultural or ethnic styles in one place, or the mimetic artificial reproduction of the notion of the place.

\section{THE CONTEMPORARY FACES OF THE GREEK CITY}

The Greek city has been affected in its recent evolution, during the last century, by various indigenous or external agents in such a manner that it led to the development of a remarkable diversity in its urban image, but mostly in its urban structure. The Greek city (in this study, the 'Greek city' is defined as the built space in general, city cores, sub- and ex-urban settlements that participate in contemporary urban evolution) appears today with a number of different 'faces' because it is composed of a variety of cityscapes connected to several spatial entities, historical periods and crucial coincidences in the social and political field. Obviously the large number of 'faces' of the Greek city leads very often to conflicts, contradictions, surprises, and also to particular social exclusion phenomena. Even if we cannot claim that the boundaries between these 'faces' are very clear, an effort is made to approach the best known of these 'faces' in order to define some of their special characteristics.

\subsection{The historic city}

Greece, as a country with a rich history and long-time continuity in urban life from the ancient times up to the present, has urban centers that retain the remnants of the past in every scale (in a building unit scale and in a city scale). There still exists entire historical complexes or just special value historic fractals within the contemporary fabric.

Therefore, the Greek city has, in many cases, an alive, historic, urban face with an intense perceptional emergence [18]. Furthermore, historic sites, beyond their transformations in the form of new buildings inputs or urban design, are still characterized by a number of spatial, urban virtues. We can quote among others: the human scale and the notion of the neighborhood; interesting building 
typology and architectural ideas usually referring to the significant quality of daily life initiatives (internal yards, etc.), and finally several public buildings and courts that emerge as points of reference or city landmarks.

Nevertheless, the historical 'face' of the Greek city is, today, exposed to the danger of negative shifts, which often proceed through the following phases: (i) abandonment of historic shells (from their owners and the public authorities); (ii) the progressive collapse of a number of old constructions because of the lack of preservation; (iii) additional constructions, increasing building mass, and aggravating the environment; (iv) gradual degradation of the quality of life, social withdrawal, and alienation from the surrounding urban areas.

Even if in some cases policies for preservation and protection of historic centers have yielded results [19], it can be concluded that in a large number of Greek cities the above-mentioned changes had also affected the historic physiognomy and their character causing significant urban problems.

In advance, it can also be concluded that the city and its activities are expanding today at a distance from the historic places, in parts of the contemporary expansion fabric, which rests, in most of the cases, in discordance to meanings of historicity and the traditional cultural environment. The connection and the relation (perceptional, functional, and symbolic) of these new city districts (highdensity residential areas around city centers, suburbs and exurbs, junctions-city entrances) with the historic centers and monuments could be a future action demand for the historic 'face' of the Greek city to be reinforced.

\subsection{The planned and designed city}

The establishment of the Greek state in the early 19th century is connected to innovative, for that time, town planning policies. It is well known that during the Kapodistrian and the Ottonian periods (1828-1932 and 1833-43, respectively) Greek and French military engineers and Bavarian architects, undertook the design of the new city plans (Rymotomiko Schedio) for many Greek cities, implying, at the same time, figures of neoclassical morphology brought from western and central Europe on the existing medieval-ottoman fabrics [20, 21]. Central areas of cities such as Patras, Tripolis, Nafplion, Argos, Korinthos, Ermoupolis, Chalkida, Peraeus, and Athens itself (Fig. 1) are representative cases of this procedure. Moreover, in the following period, and up to the beginning of the 20th century, a large number of plans are setting the bases of the urban development of a big part of the expanding Greek urban space [22].

It is obvious that these processes have formed just fractal 'faces' of a designed city, allocated mainly to the central areas that cover only a small proportion of the total city surfaces. It is, nevertheless, very characteristic that even though the dream of these old plans was to an extent altered during the last decades, mainly through the increase of the permitted building mass, these areas still retain significant elements of urban quality, a fact that forces us to consider them as separate entities within the city. For example, the proportion of building covered space to public open spaces is kept at a good level, an adequate relation of the street with the facade's height, a self-orientation capability, a hierarchical structure of road networks and urban space as a result of the differentiation of the street's width; and finally a minimum feasibility for pedestrian mobility through the neighborhoods.

\subsection{The recent, dynamic, 'unplanned', and arbitrary city}

The radical postwar development of the Greek city expansions, mainly during 1950-80, had unfortunately moved the Greek city far away from the model of the planned and designed city of the 


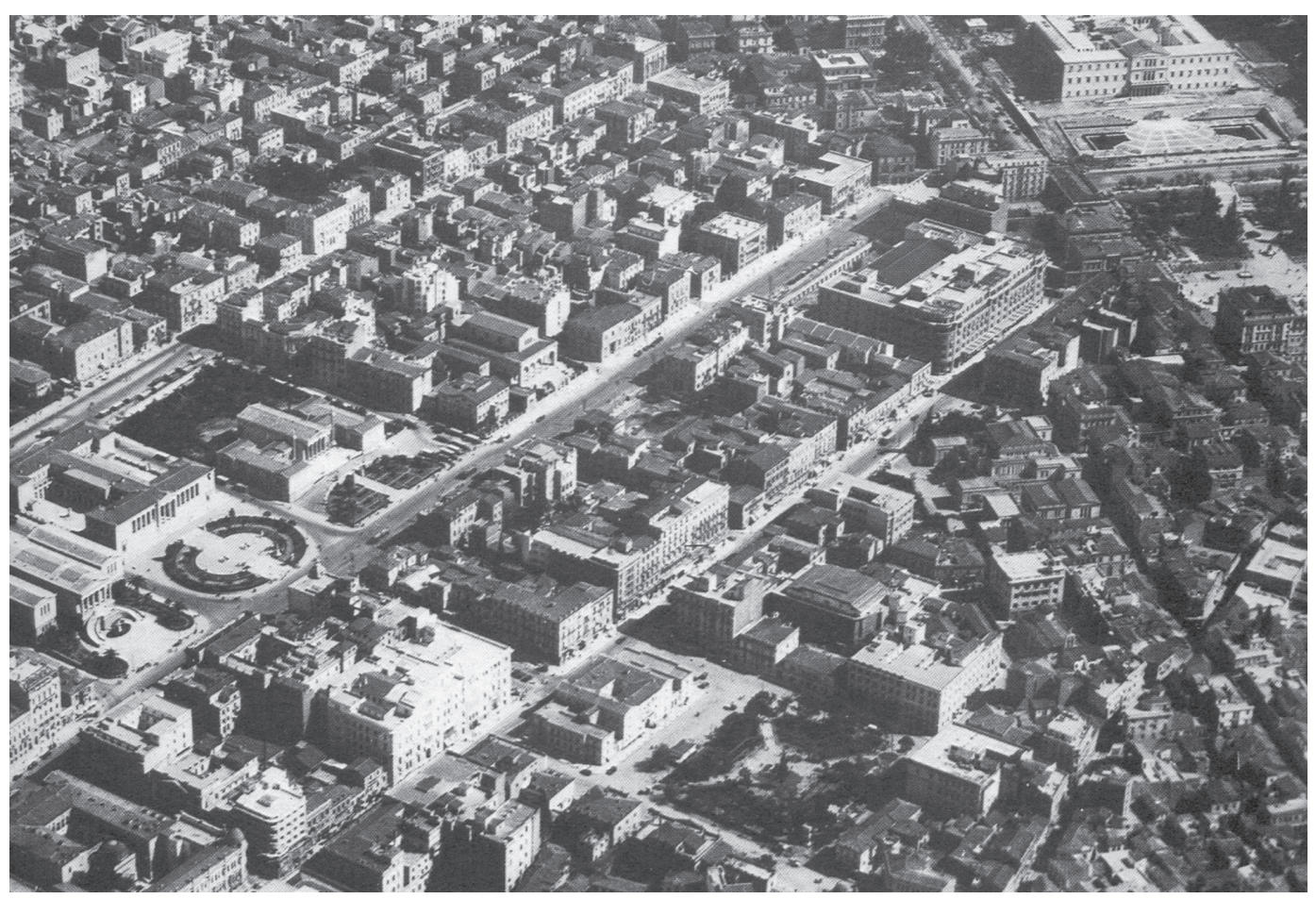

Figure 1: The central district of Athens (1932) as a result of the implementation of the planning for the new capital of Greece 1833-37 (Kleanthis, Schaubert, Klenze, Gaertner, Hoch). Source: Commercial Bank of Greece, Neo-classic architecture in Greece, Athens, 1967.

19th and the early 20th century, establishing a new 'face', that of the dynamically expanded but undersigned city. Its basic attribute is the dramatic increase of the built volume and urban densities, respectively, through the prevailing of 'polykatoikia' (multi-storey residential building) as the basic building model and 'antiparohi' [23] (a quid pro quo process, land for apartment's ownership) as the main mechanism of urban space production.

Some typical attributes of this urban area are, among others, the lack of a clear perception of the urban structure, the absence of a hierarchy in the various urban elements, the disarticulation of the neighborhood (as an urban and social cell), the relatively high building heights, the blind sidewalls, the absence of a private open space except from the narrow balconies running through the entire facade, and finally the lack of trees and vegetation in both private and public spaces (Fig. 2). From a planner's view, this unsettled and unorganized city does not hold any interest with respect to its structure and function, and also with respect to its form and image, and can claim as its only benefit its capability to emerge, in some cases, as a neutral background on which landmarks and significant for centuries - features and landscapes are presented and revealed, transmitting a notion of identity.

The scope of maximizing land profit [24] had also led to a sequence of new negative inputs for the Greek city, which are connected both to the establishment of illegal practices of the small and medium construction agents and also to the weakness of any possible intention for advancing architectural quality or protection by the elimination of open public space. 


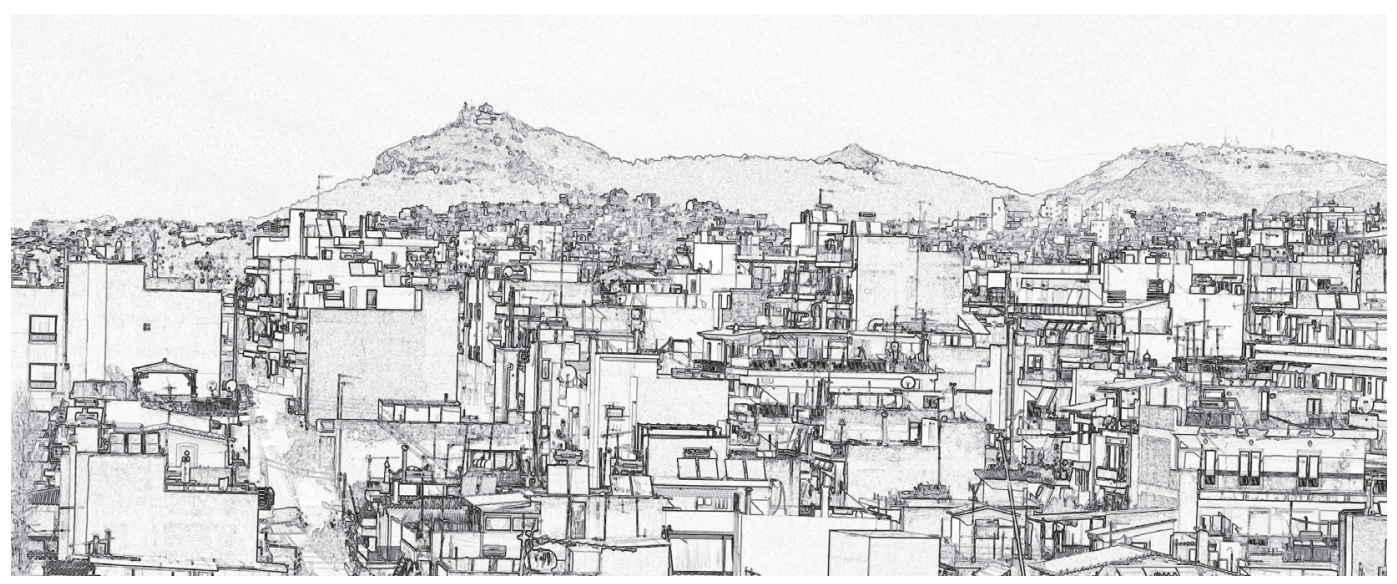

Figure 2: Athens, Ag. Dimitrios/Dafni 2005. A typical image of the new dynamic and "unplanned" Greek city. Main characteristics: great building heights, blind sidewalls, solar collectors and TV antennas on the unexploited roofs, lack of color, lack of green. In this dull image, the hill of Lykabettus distinguishes itself as the only interesting landmark.

There is a common belief that applied planning insufficiency has been a main determinant of the formation of the contemporary face of the Greek city. It could be characterized as 'unplanned' $[25,26]$ despite the fact that during the last half of the 20th century many city plans have been carried out and approved. These plans had the limited goal of an area's 'annexation in the official plan' by tracing the new urban fabric, i.e. defining the blocks and the streets, without even taking in account the natural characteristics of each place (land unfolding, streams, forests, etc.), in most of the cases [27].

The lack of planning or any other significant state intervention, in covering housing and functional needs as well in urban planning control, has led to an additional conflict, as it promotes a 'laissezfaire', pushing individuals and social groups to act by themselves. Arbitrary building is one of the most substantial forms of self acting on the urban space. This has been expressed, in the case of urbanized areas, by smaller or bigger declines from the emerging building regulations (floor addition, turning open spaces into closed, etc.) [16], while in the case of sub- and ex-urban zones left for urban sprawl (Fig. 3), by encroaching upon and illegal building in public or private properties, forests, or streams, inside or outside the official city plan [26]. Nowadays, even though the 'arbitrary' building phenomenon, at least for primary residential needs, is limited compared to the past, it has not been possible to fully eliminate it. Legalization of arbitrary buildings and other constructions, promoted by the state from time to time, is definitely a practice that does not resolve the problem but only postpones it instead $[22,26]$.

\subsection{The 'rural' and holiday city}

Despite the fact that Greek Planning Law has defined, from the beginning of the 20th century, the term 'approved city plan' (Rymotomiko Schedio, L. O. of the 17.7/16.8.1923), in order to set a framework for urban development, this regulation was later modified by Presidential Orders according to which building is also permitted outside the boundaries of this plan and in every corner of the Greek space, such that several preconditions are satisfied [22]. 


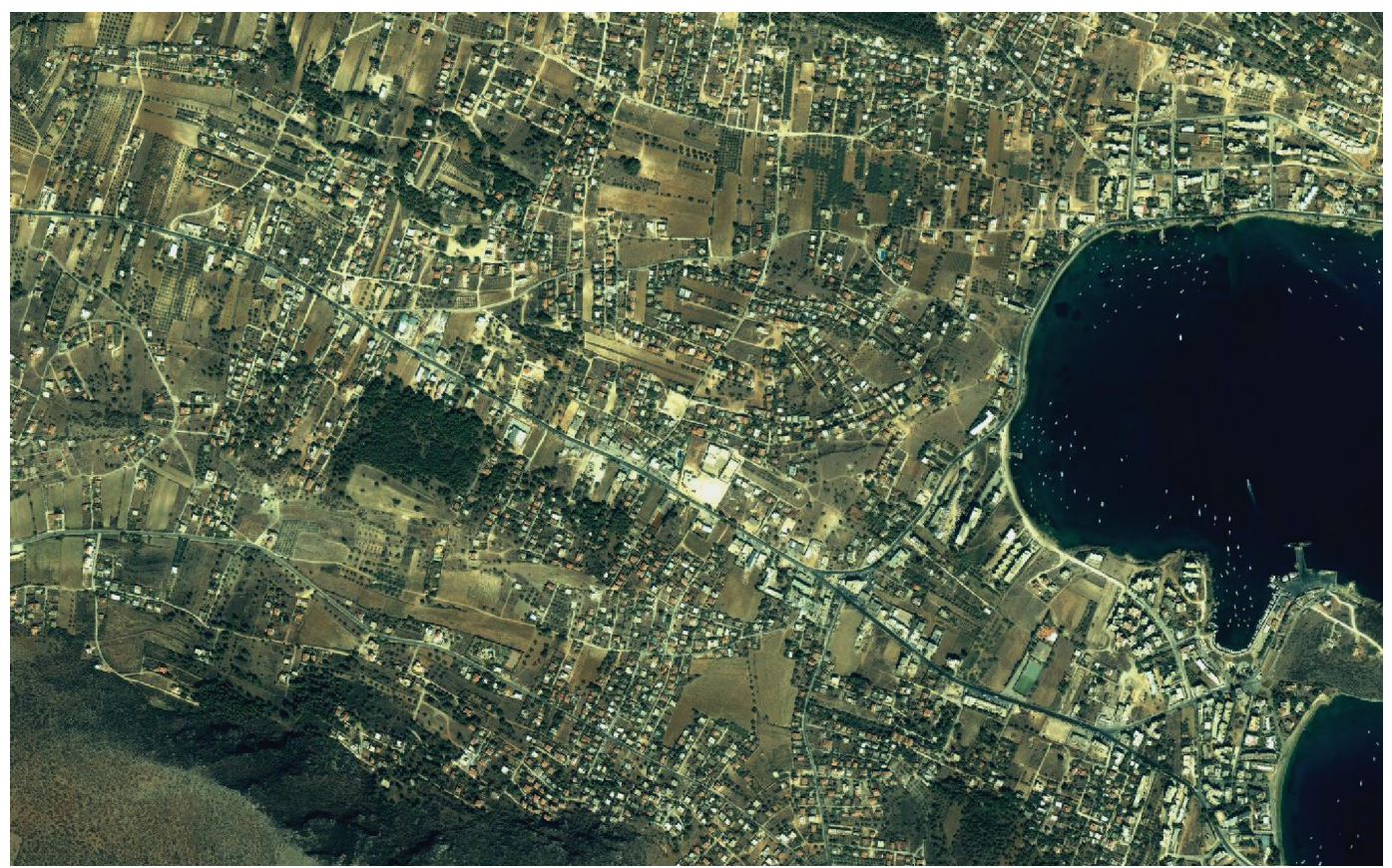

Figure 3: Attika, Porto Rafti: A typical case of urban sprawl in the ex-urban space. Source: Telenavis 2001.

As a result, there is an expanded sprawl consisting of networks of legal, residential, or other activity buildings within the rural space surrounding the conurbations. The evolution of the Greek city of today is increasingly tending to adopt new urban structures that could be easily described as low-density quasi-urban-rural settlements, allocated in zones of high attractiveness, such as the zone next to the city boundary, coastal zones (Fig. 4), as well as in zones along the main road axes where the special building regulation status and relaxations capability benefit urban development [28]. The progressive and unbalanced increase of urban density in these rural or forest land areas creates the conditions for a perceptional paradox: the 'rural city'.

A 'rural city', usually unplanned and underdesigned, is dynamically developing and to a large extent 'arbitrary'. In some cases it is seen with a special 'face', that of a holiday or vacation city. In fact, it is mainly about zones of secondary or holiday homes, developed during the last decades, also known as 'weekend cities', which are vastly transformed into dynamically developing urban expansions, as many them have turned attractive for first homes [26, 29]. The problems arising from the described pattern of a 'rural city', with or without its holiday versions, are very well known locally. Some of these problems are the vast alteration and degradation of the natural environment and physical landscape, the irrational land management and elimination of high productivity agricultural land, land use conflicts, the high cost for the construction and maintenance of infrastructure networks undertaken from the entire society, and finally a number of environmental damages due to improper waste management.

Of course, demonstrative voices are also heard, demanding the prohibition of building outside the official plans, either in an immediate and radical way or in several progressive phases $[22,26]$. Additionally, few recent regulations are moving in this direction, limiting the possibility of building 

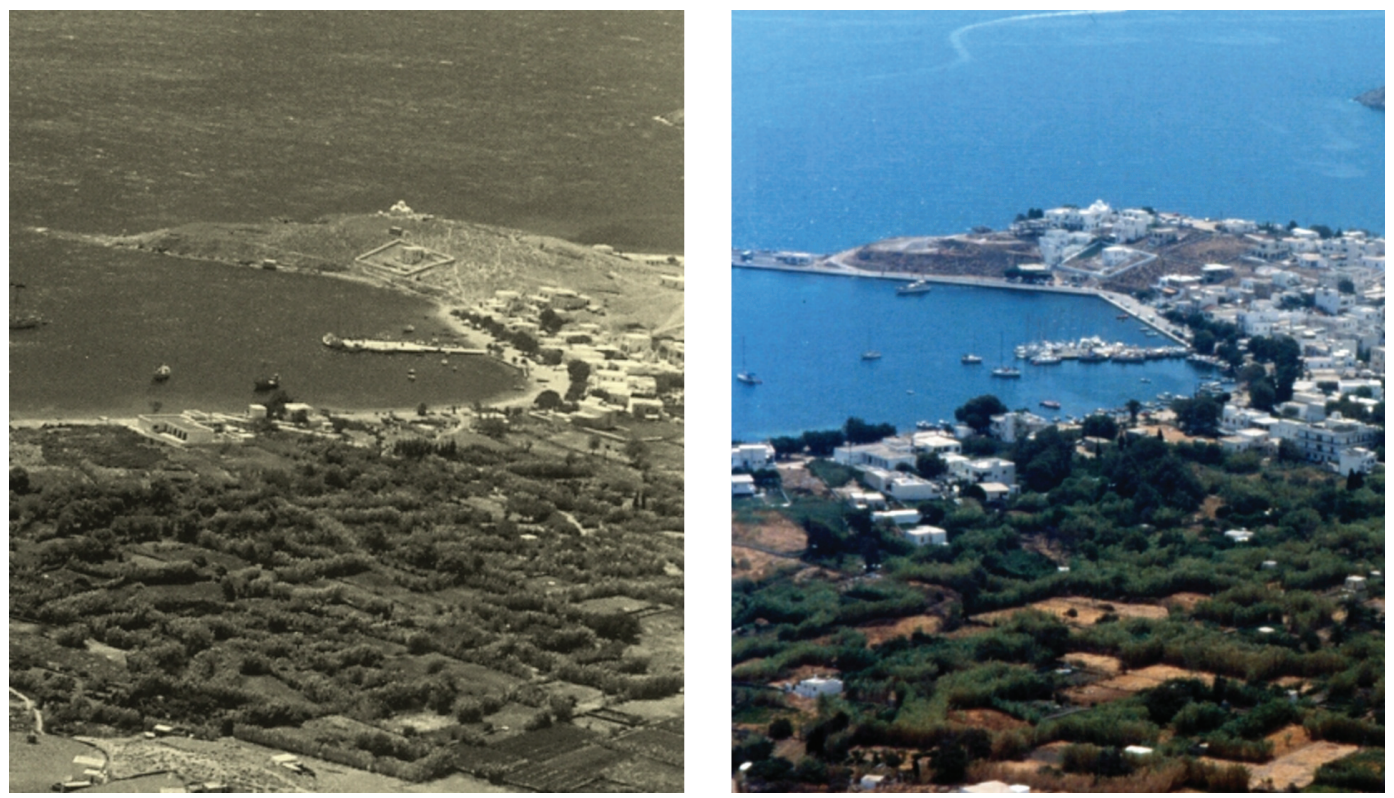

Figure 4: Island Serifos: Comparative comparison of the situation in 1963 (left) (Source: McCabe, R., Greece: Images of an Enchanted Land, 1954-1965, Patakis: Athens, 2004) and 1990 (right). The idyllic and peaceful landscape is gradually replaced by scattered, unplanned, and unorganized residential, tourist, and vacation facilities.

in agricultural or forest land, especially for the Aegean Islands. Nevertheless, to date they have not managed to act as a pilot for a wider planning and institutional reformation.

\subsection{The marginalized city}

The allocation of urban, residential areas next to or along the boundaries of huge industrial installations (oil refineries, shipyards, iron and steel industries, etc.) is undoubtedly linked to considerable burdens, sorting these zones at the city margin category. The lack of any policy or action for the reduction of these conflicts, the resolution of any problems, and the extremely limited investment in urban environmental improvement (technical or social infrastructure, green areas, etc.) leads to images of a forgotten or abandoned city, intensifying the existing social marginalization.

It is obvious that these disadvantaged areas host socially marginalized demographic groups (Roma, repatriate Greeks from the ex-USSR, foreign immigrants, etc.) [20]. The example of the Roma campuses at a number of points in the Athens metropolitan region or other smaller cities is very characteristic. These are temporary settlements, usually constructed from cloth, paper, or plastic material, without electricity or water supply and also without any basic urban or social infrastructure. In these areas phenomena such as unhealthy conditions of living, widespread analphabetism, lack of a substantial functional design are very common occurrences that enhance the increase of the notion of marginality. All these are not just isolated problems that are limited in their boundaries, but they may cause disadvantages to the whole city, as they consolidate exclusion and inequality conditions, turning them into 'normal' aspects of the city, unacceptable for a sustainable and well organized European city. 


\subsection{The discussion for a "natural'/environmental city}

It is commonly known that sensitivity in the issues of environmental planning is increasing throughout Europe, emphasizing among others the need for facing facts such as the global environmental problem, or more local issues such as the urban sprawl and land waste. Terms such as 'compact city' [30] or the more recent 'connected city' [31] are entering this discussion.

Considering the Greek city, it is also acknowledged that the vast and unplanned development of the last decades has led to a degradation of its natural and urban environment. Not only the continuous and lawless pollution but also the improvident and catastrophic management of natural resources (land, underground water, coastlines, forests, and agricultural land) has very quickly led to this adverse evolution.

Despite all these negative shifts the Greek city has passed through during the postwar period, it is surprising to note that to date it has retained fewer or more elements from its natural environmental 'face'. This is mainly because for a number of cities the natural landscape enclosing or surrounding the city coincides with their identity or they are accepted as strong and special identity factors. This landscape in many cases may be a particular unfolding (Kavala, Ermoupoli, Edessa, etc.), while coastal zones and seascapes are equally important as identity creators.

In a few cases these natural elements happened to be at the center of integrated urban interventions, thereby reinforcing the 'natural' face of the respective cities (e.g. the restoration and environmental upgrading of Ag. Nikolaos Park at Naousa, the restoration of the surrounding landscape of Chrysopigi Monastery in Chania, the environmental intervention at Krya - Livadeia) [4] (Fig. 5). All the abovementioned actions are examples of the efforts toward alignment of Greek spatial policies with the European directives, which unfortunately are still limited resulting in the considerable lag in this direction [32].

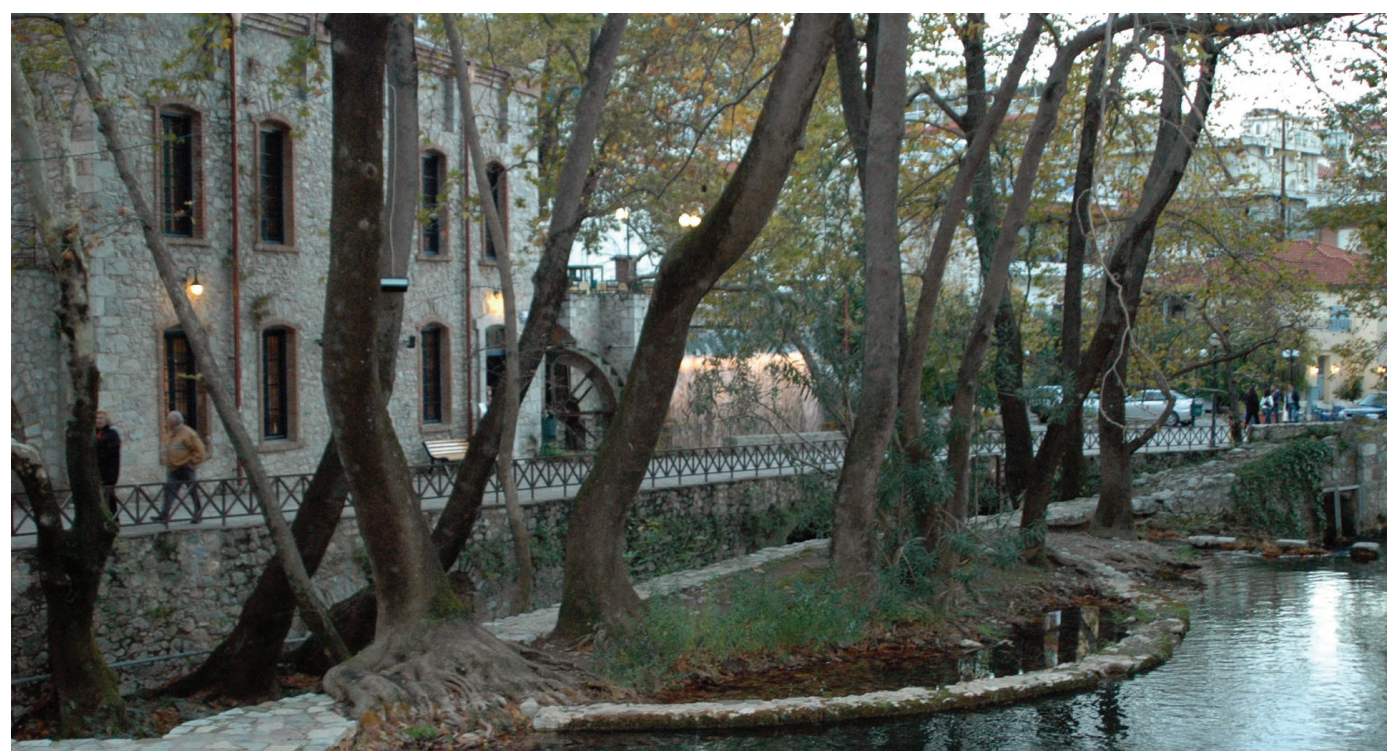

Figure 5: Livadeia, 'Krya' district, 2005. A successful environmental intervention, which aimed to protect the physical environment, to upgrade traditional buildings and monuments as well as to smoothly integrate new facilities for visitors. 


\subsection{The globalized face of the Greek city}

The last-examined Greek city 'face' is the one immediately affected by the global influences. Obviously, this general dimension is an area of interest for European city scholars, but beyond its specific relation to our case, in Greece this is considered to be a relatively recent evolution, which in the current phase seems to result in several conditions in the urban space based mainly on two of its aspects: the first is related to the mixing and integration of the new population due to foreign migration within the Greek society, and the second is related to the prevalence of the global models of living, consuming, and recreating.

In spite of the fact that the setting of foreign immigrants does not seem to trigger strong ups and downs in the urban space, the global urban notion is already affected through widespread globalized uses and activities (e.g. fast food restaurants, international banks and other services, global franchising firms, retail and recreational malls and multiplexes), and more specifically through the architectural style by the use of a global morphology (new dynamic forms from metal, glass and steel, etc.), which to the extent it is applied establishes a remarkable diversity contradicting the homogenous image of the postwar urban expansions (Fig. 6).

These phenomena have already been quoted and analyzed in the frameworks of a technical or scientific discussion or through the mass media. Most of these views carry a skepticism that requires the Greek society and the Greek city to develop defensive attributes on the possibility of an 'alteration' of the typical, traditional, local characteristics and morphology.

It is certainly obvious that such views will make it very difficult to contribute to the beginning of several feasible interventions, especially in the framework of an integrated and open society and a relatively open city. We would rather support a view that accepts global influences as a challenge, adopting their positive influences, during the process of the planning policy formation, considering the need for upgrading the city image. A possible refusal in planning and design for the embodiment, the adjustment, and the regulation of the new trends in a compatible way will definitely leave space for uncontrolled and unplanned actions, with unforeseen and maybe negative results for the Greek city.
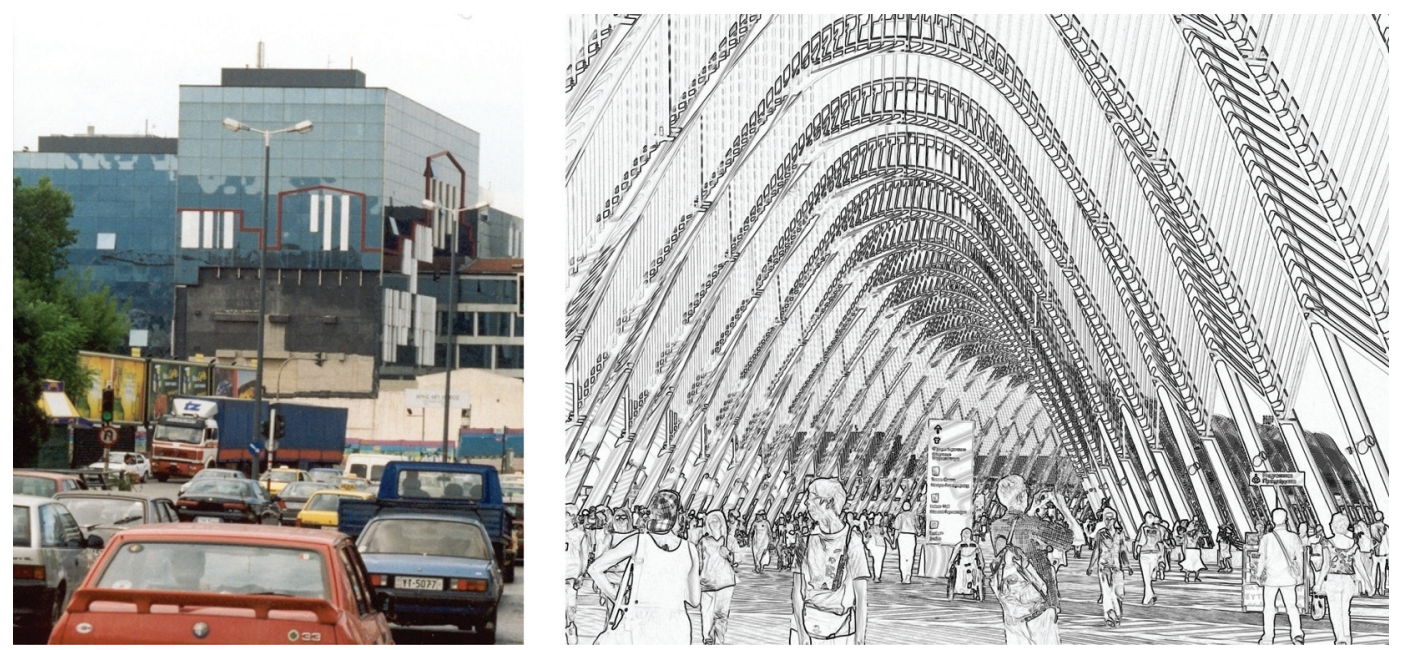

Figure 6: The globalized face of the Greek city. The case of Athens. Kifisias avenue, one of the quickest developing commercial and business zones in Athens (left). A characteristic view of the built environment created recently for the 2004 Olympics (right). 


\section{CONCLUSIONS ABOUT RECENT DYNAMICS}

Undoubtedly, every evidence (historical, social, political, economic, planning, etc.) affecting past urban space evolution has created the background, the 'canvas', for any future change of the city space in Greece and in Europe and worldwide. It has been shown, additionally, that to the extent that this 'canvas' is different for the Greek and the European paradigm, the more recent elements of the urban image will also evolve under different constraints. At the same time, we acknowledge that today the global scene is dominated by evolutions of a global influence and dynamics, affecting the structure and the image of the cities immediately in a uniform way. These dynamics emerge as strong homogenizing agents for the image of the urban space, as well as for its function and respective problems wherever these cities are.

The aim of this study is to quote several significant 'faces' characterizing the contemporary city, shaped or being shaped at the moment. The analysis has shown that the approached 'faces' are results of the same dynamics, corresponding to more or less common aspects of urban evolution but motivated by different agents and conditions ('canvas') in the Greek rather than the European paradigm. So differences are expected in each and every case of future evolution (Table 1).

These dynamics presented in Table 1 are listed in a cluster sequence that begins from the less to the more 'globalized' ones. More specifically, historical dynamic includes the trends and images related to urban morphology of the past; spatial dynamics are called the fundamental determinants of the pre-existing urban evolution, different in every single place; social dynamics refer to the new trends in migration, the globalized life style, and the inequalities deriving form the free market function; environmental dynamic summarizes the will for a sustainable city; and finally 'global' dynamics contain the holistic notion of globalization, technological advance, and the importance of 'experience' in the city life.

1. First, the policies for the reinforcing of the historical identity of the urban space are an emerging dynamic in Greece and in the rest of Europe. Despite the fact that today the dominance of the private initiative in planning and management of these places leads to an overdose of retail and recreational activities and the consequent exclusion of several social groups, which these uses are not attending to, it is well known that the European city had - during the postwar

Table 1: The evolving dynamics of the contemporary European and Greek city.

\begin{tabular}{lll}
\hline & \multicolumn{1}{c}{ European city } & \multicolumn{1}{c}{ Greek city } \\
\hline Historical dynamic & - The city of historic identity & - The historic city/fractal \\
& & monuments \\
Spatial dynamic & - New urban structures & - Unplanned city \\
& - Expanding city & - Rural' city \\
Environmental dynamic & - Totalizing suburb & - Holiday or residence city \\
& - Sustainable city policies & - Interventions toward an \\
Social dynamic & - element & environmental perspective \\
Global dynamic & - Gulticultural city & - Immigrants city \\
& - Virtual city & - Marginalized city \\
& - Global city & - Virtual city \\
\end{tabular}


period - considerably enhanced its historic face through systematic actions of preservation and regeneration of the historic centers.

In contrast to the above, the Greek city has suffered in this field, as today many parts of the historic fabric in the Greek cities are characterized by either degradation and abandonment or an overexploitation and the full control by economic activities of the private sector (i.e. single or franchise firm cafés and restaurants occupying open space, etc.) with further perspectives being not so promising. Furthermore, the connection and the linkage (visual, functional, and symbolic) of the newer urban areas with the neighboring historic centers and monuments would offer the capability of a substantial reinforcing of the city's historic identity.

2. Spatial dynamics form the second basic cluster of dynamics. Both the European and the Greek city are today influenced by the global evolutions in the fields of technology (internet, communications, etc.), urban mobility, and safety as well as by phenomena of urban sprawl and scales collapsing. Nevertheless, these constraints do not appear with the same gravity in both the cases. If, for example, some recent issues of spatial dynamics in the European paradigm are the continuous expansion of the metropolitan conurbation and the formation of 'totalizing suburbs' (rearticulating the spatial, centrality hierarchies), a significant tension in the evolution of the Greek city is the diffusion and the sprawl of urban expansions over the rural space surrounding the cities (primary and secondary residential areas), generating new invertebrate urban areas that are unable to support the power centers. Under this aspect, although the role of the traditional metropolitan centers is not threatened, various structural, environmental, and functional problems are born, highlighting the consolidated weaknesses of the Greek planning system.

3. In the recent years, a campaign about the need for environmental upgrading and protection of the urban space has been developed all over Europe. The meaning of sustainability is therefore more and more connected to urban policies, focusing among others on the rational management of urban land, sustainable urban mobility, energy saving, and clever systems of water and waste management.

Environmental degradation of the Greek urban space in total is very considerable mainly due to the unplanned postwar urban development. The successful interventions in this direction are very few, compared to the European paradigm. These actions, even if they are considered as pilot efforts aligned toward the European directives, are unfortunately still few and fragmented.

4. 'Multiculturalism' is in the center of the interest in the social field as a part of the dynamic evolution of the European city. While in western and mainly in central Europe cultural mixture within the urban space has a continuous tradition, in Greece such phenomena were rarer especially during the 20th century. The recent diffusion of immigrants over the Greek urban space has, to date, avoided the empowering of ghettos. Nevertheless, a large number of them are concentrated in degraded zones that are already at the city's margins.

Moreover, social exclusion conditions are also formulated through formal urban interventions and planning. A gentrified city describes a well-known tension in the European urban space, as a result of radical regenerations of private-public partnerships. This has not happened in Greece to such an extent because of the mixed land uses profile of the urban space [33] and the general weakness in implementing interventions and plans involving the public sector effectively. The fortification of the small property ownership in every transforming zone leads just to a 'light' version of a Greek gentrification, limited at the moment to the historic centers and the 'showcase' areas of mainly Athens.

5. Finally, urban space develops special dynamics related to the new environment and the modes of a global community. The European city has already embodied many of them, expressed at a spatial level and it is also evident in the influence of global images promoted through the virtual 
representations (cinema, TV, mass media, and the web, etc.). In the framework of the international competition between metropolises, the attractiveness of the urban space is therefore promoted, emphasizing dimensions such as recreation, green areas, culture, and diversity as parts of the image or experience offered and less as a structural part of the city's function.

These globalized standards of lifestyle, consumption, and recreation are also emerging in the Greek city. These are reflected not only in its architectural dimension (international style, global morphology) but also in the rest of the urban scales, regarding land uses and activities. At the same time, a 'quasi-virtual' version of the Greek city is revealed through two facts: first, the multiplication of the isles of 'virtual and supra-urban experience' (malls, cineplexes, fun parks, etc.) as real places in the real urban fabric; and, second, through undertaking and organizing important international events (2004 Olympic Games) accompanied by the building of a 'media' image of the city, used for the promotion of a refined profile and physiognomy through media networks.

From the above, it is clear that there are a large number of common constraints between the Greek and the European urban image evolution, with respect to their underground dynamics and their perceptional notion. Besides, in the framework of a unified European space, even the autonomous trajectories cannot avoid inclining toward the European mainstream, even if not coincidently, by the progressive adaptation of common references to it.

Nevertheless, undoubted particularities (institutional, developing, social, etc.) will always exist, retaining the differentiations of the Greek paradigm. For example, its extremely multi-face dimension, at the moment, does not seem to be altered by the external homogeneity dynamics, but it still retains small or large zones of local diversity. Obviously, conflicts appear within this context; on the one hand, serious structural, social, planning, aesthetic, and also daily life problems continue to appear and, on the other hand, important pre-existing qualities and values (social and cultural particularities, etc.) continue to be threatened by elimination.

In these terms, and as the Greek city is formulating its direction, balancing between the positive and the negative determinants of its various faces and being open to any global or European influence, strategic planning could play the role of the regulating coordinator, tracing the future steps. In other words, strategic planning can respond, among other demands, to the particular diversity demands, smoothing and balancing any conflicts thereby leading to a visual homogenization, which is definitely undesirable. Hence, if in some cases it is necessary to give priority and protect positive indigenous faces of the city (historical, environmental face, etc.) using tools and influences from the European practice, in other cases further expansion of its negative faces must prevail, acting in the direction of a radical regulation and a short-term solution for the problems generated (the dynamic unplanned face, 'arbitrary' expansions, urban/rural sprawl, and the city of the margin).

Although the central issue (inside and outside Greece) is the need for improving the social acceptance and the feasibility of planning, we state that the specific need for the satisfaction of a number of parameters related to the human and social nature is not easy; it can neither be institutionally regulated nor can it be promoted through short-term actions. Among them, we would particularly mention: the need for a planning consequence on the part of the state and the local governments; a well-organized and productive collaborative procedure involving citizens in the planning process; building, among the society, a planning culture and a planning morality as well as environmental sensitivity; and finally a commonly acceptable and socially balanced attribute and presence in the city on behalf of each one of the inhabitants or any legal entities themselves.

The promotion of, even of a part, the above-mentioned points will certainly create beneficial conditions for balancing against the conflicts and the coexistence of the various 'faces' of the Greek 
city, and at the same time assist the smoother embodiment of the new global influences. The city 'face', which is used as an analysis tool in this study, is in fact nothing less than the material concrete expression of the really complicated, immaterial urban dynamics and trends.

\section{REFERENCES}

[1] UN Centre for Human Settlements (HABITAT), Cities in a Globalizing World. Global Report on Human Settlements, Earthscan: London, 2001.

[2] Bridge, G. \& Watson, S., A Companion to the City, Blackwell: Malden, 2003.

[3] LeGates, R. \& Stout, F., The City Reader, Routledge: London, 2000.

[4] YPEHODE, Declaration for the Cities and the Rest of the Human Settlements in the New Millenium, Habitat Agenda, Istanbul, 5.6.2001, Department of Housing Policy: Athens, 2001 (in Greek).

[5] Hall, P. \& Pfeiffer, M., Urban Future 21. A Global Agenda for the Twenty-first Century Cities, E \& FN Spon: New York, 2000.

[6] Angelidis, M., Sustainable Urban Development of Cities in Europe and in Greece, YPEHODE: Athens, 2004 (in Greek).

[7] Barbopoulos, N. \& Baltas, P., Next Stop: Lost Avenues. A Tour to the Cosmogonia of American and European Metropolis, Futura: Athens, 2004 (in Greek).

[8] Aravantinos, A., The dynamic, flexible and self-sustained city: its capability for 'offence' and 'defence' in order to ensure its future. Proc. of the 38th International ISoCaRP Congress: The Pulsar Effect in Urban Planning, Athens, pp. 51-61, 2002.

[9] European Regional Science Association, Proceedings of Images of Future Cities: From Industry to Advanced Services. Perspectives of European Metropolitan Regions, Dortmund, ed. L. Helenius-Maki, pp. 16-17, 2002.

[10] Marcuse, P. \& Van Kempen, R., Globalizing Cities. A New Spatial Order? Blackwell: London, 2000.

[11] Massey, D., Allen, J. \& Pile, S., Understanding Cities. City Worlds, The Open University: London, 1999.

[12] Haughton, G. \& Hunter, K., Sustainable Cities, Jessica Kingsley Publishers: London, 1994.

[13] Rogers, R., Cities for a Small Planet, Faber \& Faber: London, 1997.

[14] Lefas, P., Siebel, W. \& Binde, J., Tomorrow the Cities, Plethron: Athens, 2003 (in Greek).

[15] Short, J.R., The Urban Order. An Introduction in Cities, Culture and Power, Blackwell: Massachusetts and Oxford, 1996.

[16] Ioannou, B., Polychronopoulos, D., Serraos, K. \& Zifou, M., Transformations in the image of the Greek city. Motives and effects on the contemporary urban fabric. Conference Proceidings: Metropolitan Planning and Environmental Issues, AESOP: Grenoble, 1-4 July, 2004.

[17] Chaplin, S., Heterotopia Deserta: Las Vegas and other spaces. Designing Cities, ed. A. Cuthbert, Blackwell: Malden, pp. 340-354, 2003.

[18] National Technical University of Athens, Laboratory of Urban Design, The Physiognomy of the Greek City, Athens, 2000 (in Greek).

[19] National Technical University of Athens, Faculty of Architectural Engineering, Unification of the Archaeological Sites of Athens: The Procedure of Materializing a Dream (conference, 15.5.2001), Athens, 2001 (in Greek).

[20] Polyzos, I., Athens capital of the hellenism, at: Ministry of Culture. Athens in the 20th Century, Athens As It Does Not Appear, Athens Cultural Capital of Europe, Athens, pp. 24-32, 1985 (in Greek). 
[21] Tsakopoulos, P., The Greek city and the neoclassicism: Greek urban design in the 19th century. Archaiologia, 65, pp. 31-41, Athens, 1997 (in Greek).

[22] Rizos, S., The self refutation of the Greek planning law. Honorable Volume for the 75 years of the Council of the State, Sakoulas: Athens, pp. 1191-1203, 2004.

[23] Antonakakis, D.S., The post-war 'polykatoikia' as the public space creator - a first approach. Athens in the 20th Century, Athens As It Does Not Appear, Athens Cultural Capital of Europe, Athens, pp. 129-135, 1985 (in Greek).

[24] Mantouvalou, M., Urban land profit. Land prices and urban space development procedures II. Doctrine for the spatial analysis in Greece. Greek Review of Social Researches, EKKE: Athens, pp. 53-80, 1996 (in Greek).

[25] National Technical University of Athens, Laboratory of Planning Methodology and Spatial Adjustment, EKKE. Vacation Residence and Spatial Development in Greece, Athens, 1998 (in Greek).

[26] Romanos, A., Athens, Urban Issue from the Citizens View, Athens, 2004 (in Greek).

[27] Aravantinos, A., Urban Planning, for a Sustainable Development of Urban Space, Symmetria: Athens, 1998 (in Greek).

[28] European Commission, EC Directorate General XVI/European City Planners Association, European Urban and Regional Planning Awards, Luxembourg, 1999.

[29] Economou, D., Planning policy in Greece: structural characteristics and contemporary tensions. City and Space from the 20th to the 21th Century, Honorable Volume for Prof. Aravantinos, eds D. Economou, G. Sarigiannis \& K. Serraos, NTUA School of Architecture, University of Thessaly Department of Planning and Regional Development, The Greek Planners Association: Athens, pp. 371-382, 2004 (in Greek).

[30] Jenks, M., Burton, E. \& Williams, K. (eds), The Compact City: A Sustainable Urban Form?, E \& FN Spon: London, 1996.

[31] European Council of Town Planners, The New Charter of Athens the European Council of Town Planners' Vision for Cities in the 21st Century, Lisbon, 2003.

[32] Serraos, K., Kommunalplanung in Griechenland und Österreich, L. B. Institut zur Erforschung von Methoden und Auswirkungen der Raumplanung: Wien, 1996.

[33] Maloutas, Th. et al., The Cities - The Greek Socioeconomic Atlas, EKKE/Thessaly University Press: Athens, Volos, 2000 (in Greek). 